\title{
ANALISIS PENAWARAN DAN PERMINTAAN KAYU BULAT UNTUK PEMENUHAN KEBUTUHAN INDUSTRI KAYU LAPIS, KAYU GERGAJI DAN PULP DI INDONESIA
}

\author{
Erwinsyah $^{1}$, Harianto $^{2}$, Bonar M. Sinaga ${ }^{3}$, Bintang C.H. Simangunsong ${ }^{4}$ \\ ${ }^{1}$ Fakultas Pasca Sarjana, Universitas Indraprasta-Jakarta \\ ${ }^{2,3}$ Fakultas Ekonomi dan Manajemen, Institut Pertanian Bogor-Kampus IPB Darmaga Bogor \\ ${ }^{4}$ Fakultas Kehutanan, Institut Pertanian Bogor- Kampus IPB Darmaga Bogor
}

\begin{abstract}
In the last three decades forestry sector has been given important contribution to the economy of Indonesia, and during period year 1993-2005, it contributed from 1.7 to 3.1 percent. To maintain this contribution, it is needed to have a continuation raw material input, roundwood. Some studies showed that supply of raw material for wood-based primary industries such as plywood, sawn timber and pulp in Indonesia are still continuing. Therefore it needs to know the characteristict supply and demand of woodbased industry by predicting the elasticity. This paper will discuss about elasticity supply and demand of input market of roundwood from natural and plantation forests and output market of plywood, sawntimber and pulp. Data used for this study is time series, from year 1995 until year 2009. The estimation of econometric model used in this study was simultaneous (2SLS) equation or ordinary least squares $(O L S)$ if the $2 S L S$ model is not work. Data processed by Rats processing program. All predicted parameter then evaluated and checked inaccordance to the economic theory. However, not all predicted elasticity resulted from this study were used. For those could not used then data taken from references. Demand elasticity of roundwood from natural forests and plantation forests are mostly price inelastic.
\end{abstract}

Key words: wood based industry, supply, demand, estimation of econometric models, elasticity.

\begin{abstract}
ABSTRAK
Dalam tiga dekade terakhir sektor kehutanan telah memberikan kontribusi penting bagi perekonomian Indonesia, dan selama rentang waktu tahun 1993-2005, memberikan kontribusi 1.7 sampai 3.1 persen. Untuk mempertahankan nilai ini, diperlukan keberlanjutan penyediaan kebutuhan bahan baku, kayu bulat. Beberapa penelitian menunjukkan bahwa ketersediaan bahan baku bagi industri primer berbasis kayu seperti kayu lapis, kayu gergaji dan pulp di Indonesia masih berjalan. Oleh karena itu perlu untuk diketahui kharakteristik penawaran dan permintaan industri primer berbasis kayu melalui nilai penduga elastisitasnya. Penelitian ini akan membahas mengenai elastisitas penawaran dan elastisitas permintaan pasar input kayu bulat yang berasal dari hutan alam dan hutan tanaman, dan pasar output kayu lapis, kayu gergaji dan pulp. Data yang digunakan dalam rentang tahun 1995 sampai dengan tahun 2009. Model dugaan ekonometrik yang digunakan dalam penelitian ini adalah persamaan simultan (2SLS) atau ordinary least squares (OLS) apabila 2SLS tidak dapat digunakan. Pengolahan data menggunakan program RATS. Keseluruhan nilai parameter dugaan selanjutnya dievaluasi dan diperiksa berdasarkan teori ekonomi. Namun demikian, tidak semua nilai dugaan elastisitas yang dihasilkan dalam penelitian ini digunakan. Nilai yang tidak dapat digunakan kemudian dicari nilai penggantinya yang diperoleh dari berbagai referensi. Elastisitas permintaan permintaaan kayu bulat yang berasal dari hutan alam dan hutan tanaman adalah inelastis.
\end{abstract}

Kata kunci: industri berbasis kayu, penawaran, permintaan, model dugaan ekonometrik, elastisitas. 


\section{PENDAHULUAN}

Berdasarkan Undang-undang Nomor 41 Tahun 1999 tentang Kehutanan, penyelenggaraan kehutanan bertujuan untuk sebesar-besar kemakmuran rakyat yang berkeadilan dan berkelanjutan, salah satunya yaitu dengan mengoptimalkan aneka fungsi hutan yang meliputi fungsi konservasi, fungsi lindung, dan fungsi produksi. Dalam tiga dasawarsa terakhir sektor kehutanan memberikan kontribusi penting bagi perekonomian Indonesia. Penerimaan Negara Bukan Pajak (PNBP) bidang kehutanan terdiri dari berbagai jenis. PNBP bidang kehutanan yang berhubungan dengan pengelolaan hutan diantaranya Provisi Sumber Daya Hutan (PSDH), Dana Reboisasi (DR), dan Iuran Izin Usaha Pemanfaatan Hutan (IIUPH) (Kementerian Lingkungan Hidup dan Kehutanan, 2016). Selama periode tahun 1980-2005 penerimaan dari sektor ini berfluktuasi, mencapai puncaknya tahun 1997, sebesar US\$ 6.24 milyar. Kontribusi sektor kehutanan terhadap GDP periode tahun 1993-2005 berkisar antara 1.7 persen sampai 3.1 persen, dan penerimaan negara dari sektor kehutanan berasal dari Iuran Hak Pengusahaan Hutan (IHPH), Dana Reboisasi (DJR/DR) dan Provisi Sumberdaya Hutan (PSDH/IHH), periode tahun 1993-2004 berkisar antara Rp1.16 trilyun-Rp. 3.37 trilyun. Realisasi penerimaan PNBP dari PSDH dan DR hingga semester I tahun 2009 mencapai Rp 1.1 triliun atau 40 persen dari target tahun yang sama (Bisnis Indonesia, 2009). Pada tahun 2011 PNBP dari PSDH dan DR mencapai Rp 2,58 trilyun dan tahun 2012 turun menjadi 2.47 trilyun (Kementerian Lingkungan Hidup dan Kehutanan, 2016). Produksi kayu bulat berasal dari hutan alam, hutan tanaman industri, izin sah lainnya atau dari areal konversi. Saat ini produksi ratarata kayu bulat dari hutan alam 5 juta $\mathrm{m} 3$ per tahun, jauh berkurang dibanding periode tahun 1997-2000, lebih dari 10 juta $\mathrm{m}^{3}$ per tahun. Produksi kayu bulat dari Hutan Tanaman Industri (HTI) meningkat dari $600000 \mathrm{~m}^{3}$ pada Tahun 1997 menjadi 11 juta $\mathrm{m}^{3}$ pada tahun 2006. Produksi kayu bulat dari hutan alam pada tahun 2015 mencapai 5.8 juta $\mathrm{m}^{3}$, sedangkan produksi kayu bulat dari hutan tanaman mencapai 29.4 juta $\mathrm{m}^{3} \quad$ (Kementerian Lingkungan Hidup dan Kehutanan, 2016). Kayu bulat diolah oleh industri menghasilkan produk lanjutan berupa kayu gergaji, kayu lapis, wood working, block board, veneer, Chips dan lainnya.

USAID dan Bank Dunia mencatat masih intensifnya produksi kayu bulat untuk bahan baku kayu lapis, kayu gergaji dan pulp. Menurut Departemen Kehutanan (2007), beberapa kebijakan pemerintah telah menyebabkan industri perkayuan tumbuh cepat dan mengalami perubahan struktur selama periode tahun 19802005, terjadi peningkatan defisit bahan baku industri kayu gergajian dan kayu lapis (serta veneer) sejak tahun 1997, sementara kapasitas terpasang industri pulp terus meningkat. Persoalan kesenjangan penawaran dan permintaan kayu bulat merupakan persoalan jangka panjang pemerintah untuk mendukung keberlanjutan industri pengolahan kayu.

Sinaga (1989) menyebutkan intervensi kebijakan larangan ekspor kayu bulat pada periode penelitian tahun 1975-1982 berdampak kepada terjadinya penurunan produksi kayu bulat dan penurunan harga kayu bulat domestik. Rusli (1999) menyebutkan adanya keterkaitan penerapan kebijakan konservasi di Indonesia dengan pasar kayu lapis, dimana kebijakan konservasi akan terkait dengan pengurangan Jatah Tebangan Tahunan (Annual Allowable Cut/AAC) produksi kayu bulat yang mempengaruhi produksi industri kayu lapis. Di Barat Laut Pacific Amerika Serikat, peraturan konservasi berdampak kepada penurunan produksi kayu (Wear dan Park, 1994). Disisi lain, karena kualitas hutan semakin menurun, maka ketersediaan bahan baku kayu bulat industri terus menurun. Dari paparan tersebut dapat dirumuskan permasalahan bagaimana ketersediaan kayu bulat dapat mendukung keberlangsungan industri pengolahan kayu primer? Untuk itu perlu mengetahui kharakteristik supply dan demand industri hasil hutan di Indonesia, salah satunya dengan menduga besarnya elastisitas.

Tujuan penelitian ini adalah untuk mengetahui estimasi elastisitas pasar input kayu bulat dan pasar output produk primer kayu olahan. Ruang lingkup penelitian ini dibatasi pada kajian bahan baku kayu bulat untuk menghasilkan kayu lapis, kayu gergaji dan pulp. Sumber kayu bulat berasal dari hutan alam dan hutan tanaman. 
Kurva supply adalah hubungan antara jumlah barang yang perusahaan bersedia menjualnya dengan harga tertentu (Pindyck dan Rubinfeld, 2013), digunakan untuk menunjukan keinginan produsen di suatu pasar. Kurva supply memiliki kemiringan positif karena biaya marginal akan meningkat apabila kuantitas meningkat (Nicholson, 2000). Kurva penawaran sekaligus menunjukkan jumlah yang produsen bersedia dan mampu untuk menyediakan pada berbagai harga, faktor lainnya dianggap tetap (Samoelson dan Stephen, 2012). Faktor diluar harga penentu variabel supply yaitu tenaga kerja, modal dan bahan baku (Pindyck dan Rubinfeld, 2013).

Kurva demand adalah hubungan antara jumlah barang yang konsumen bersedia membeli dengan harga tertentu. Faktor di luar harga yang menjadi penentu variabel demand adalah pendapatan, selera dan harga barang lain yaitu barang substitusi dan barang komplemen (Pindyck dan Rubinfeld, 2013). Kurva demand memiliki kemiringan negatif karena nilai marginalnya turun apabila kuantitasnya meningkat (Nicholson, 2000).

Model ekonomi yang umum digunakan yaitu model supply-demand, menggambarkan bagaimana harga berperan sebagai biaya produksi dan keinginan pembeli untuk membayar pada tingkat biaya tersebut (Nicholson, 2000). Model ini dapat digunakan untuk menganalisis pasar kayu bulat dan industri primer kayu.

Menurut Pindyck dan Rubinfeld (2013), elastisitas adalah persentase perubahan satu variabel yang menghasilkan perubahan satu persen kenaikan pada variable lainnya. Elastisitas harga demand adalah persentase perubahan kuantitas demand dari produk akibat kenaikan satu persen harga. Sedangkan elastisitas harga supply adalah persentase perubahan kuantitas supply akibat kenaikan satu persen harga.Nicholson (2000) menyebutkan bahwa pada kurva yang memiliki elastisitas demand kurang dari -1 bersifat elastis, yang memiliki elastisitas demand sama dengan -1 bersifat unit elastis dan yang memiliki elastisitas demand lebih dari -1 bersifat inelastis. Untuk kurva yang elastis, perubahan harga sepanjang kurva akan mempengaruhi terjadinya perubahan kuantitas permintaan produk secara significant. Pada kasus inelastis, adanya perubahan harga akan sangat kecil pengaruhnya terhadap kuantitas demand. Teori elastisitas ini akan digunakan untuk menganalisis sensitifitas pasar kayu bulat dan industri primer kayu.
Menurut McGuyan dan Moyer (1986) faktor yang mempengaruhi demand yaitu (1) Ketahanan penggunaan barang (Durable good), (2) Derived demand, dapat digunakan sebagai bahan baku produk lain dan (3) Nilai tukar. Disebutkan juga bahwa elastisitas harga produk memiliki brang lain sebagai substitusi akan lebih elastis. Elastistias harga produk yang lebih tahan lama (durable) bersifat elastis, dan yang memiliki porsi terbesar terhadap anggaran (budget) akan lebih elastis.

\section{METODE PENELITIAN}

Lingkup kajian supply kayu bulat yaitu berasal dari hutan alam produksi dan HTI, yang digunakan untuk bahan baku industri kayu lapis, kayu gergaji dan pulp.

Menurut Timotius (2000), produksi kayu bulat Indonesia dipengaruhi oleh perubahan harga riil kayu bulat domestik, bunga riil Indonesia, jumlah maksimum tebangan kayu bulat dalam satu tahun yang diizinkan (AAC), nilai tukar rill rupiah terhadap US\$, produksi log Indonesia tahun sebelumnya. Jika perubahan harga log domestik naik, diduga produksi log Indonesia juga akan bertambah. Adam, Branlund, Daniels, Hyde serta Kuuluvainen dalam Turner (2006) menyebutkan bahwa model ekonometrika menggambarkan supply kayu sebagai fungsi dari harga kayu tegakan (stumpage price), stok hutan dan variabel lainnya. Hasil penelitian Simangunsong (2001) untuk model permintaan internasional berdasarkan data dari 64 negara terhadap tujuh kelompok hasil hutan, terdapat kecenderungan elastisitas yang sama di semua negara. Tabel 1 adalah hasil penelitian elastisitas demand di beberapa negara (Simangunsong, 2001).

\section{Estimimasi Pasar Kayu Bulat dan Produk Kayu Primer}

Estimasi pasar kayu bulat dan produk kayu primer (kayu lapis, kayu gergaji dan pulp adalah sebagai berikut:

(1) Estimasi model supply kayu bulat:

$$
\begin{aligned}
& \mathrm{Ln} \mathrm{QS}_{\mathrm{t}, \mathrm{i}}=\ln \alpha_{0}+\alpha_{1} \ln \mathrm{P}_{\mathrm{t}, \mathrm{i}}+\alpha_{2} \\
& \ln \mathrm{I}_{\mathrm{t}, \mathrm{i}}+\alpha_{3} \ln \_\mathrm{GDP}+\mathrm{e}_{\mathrm{t}, \mathrm{i}},
\end{aligned}
$$

(2) Estimasi model demand kayu bulat:

$$
\begin{aligned}
\operatorname{Ln} Q d_{\mathrm{t}, \mathrm{i}}=\ln \beta_{0} & +\beta_{j} \sum_{j=1}^{k} \ln \mathrm{Q}_{t, j} \\
& +\beta_{k} \operatorname{Ln} P_{\mathrm{t}, \mathrm{i}}+\mathrm{e}_{t, i}
\end{aligned}
$$


(3) Keseimbangan pasar: $\operatorname{Ln}_{-} \mathrm{Q} \mathrm{s}_{\mathrm{t}, \mathrm{i}}=\mathrm{Ln} Q d_{\mathrm{t}, \mathrm{j}}$

(4) Estimasi model supply industri produk primer:

Ln_Qs $s_{\mathrm{t}, \mathrm{j}}=$ konstanta $+\alpha_{0}$ trend $+\alpha_{1} \ln _{-} \mathrm{P}_{\mathrm{Qt}}+\alpha_{2} \ln$ $\mathrm{P}_{\mathrm{L}}+\alpha_{3} \ln \_\mathrm{P}_{\mathrm{t}}+\alpha_{4} \ln \_\mathrm{P}_{\mathrm{E}}+\mathrm{e}_{\mathrm{t}, \mathrm{j}}$

(5) Estimasi model demand industri produk primer:

$\mathrm{Ln} \_\mathrm{Qd}_{\mathrm{t}, \mathrm{j}}=\ln \beta_{0}+\beta_{1} \ln \_\mathrm{Gt}+\beta_{2} \ln _{-} \mathrm{P}_{\mathrm{Qt}}+\mathrm{e}_{\mathrm{t}, \mathrm{j}}$

(6) Keseimbangan pasar: $\operatorname{Ln}_{-} \mathrm{Qs}_{\mathrm{t}, \mathrm{i}}=\operatorname{Ln} Q d_{\mathrm{t}, \mathrm{j}}$

Keterangan:

- $\quad \mathrm{Qs}_{\mathrm{t}, \mathrm{i}}$ adalah supply kayu bulat, $\mathrm{P}_{\mathrm{t}, \mathrm{i}}$ adalah harga riil kayu bulat, $\mathrm{I}_{\mathrm{t}, \mathrm{i}}$ inventarisasi kayu bulat, dan GDP adalah GDP Riil, i=1,2,3 (1=kayu bulat hutan alam, 2=kayu bukat HTI perkakas dan $3=$ kayu bulat pulp) dan $\mathrm{e}_{\mathrm{t}, \mathrm{i}}$ adalah error.

- $\mathrm{Qd}_{\mathrm{t}, \mathrm{i}}$ adalah demand kayu bulat, $\mathrm{Q}_{\mathrm{t}, \mathrm{j}}$ adalah jumlah kayu olahan yang dihasilkan, $\mathrm{P}_{\mathrm{t}, \mathrm{i}}$ adalah harga kayu bulat, $\mathrm{j}=1,2,3 \quad(1=\mathrm{kayu}$ lapis, 2=kayu gergaji, 3=pulp)

- $\mathrm{Qs}_{\mathrm{t}, \mathrm{j}}$ adalah supply produk kayu primer; $\mathrm{P}_{\mathrm{Qt}}$ adalah harga riil produk primer dan $\mathrm{G}$ adalah GDP Riil serta $e_{t, j}$ adalah error.

- $\mathrm{Qd}_{\mathrm{t}, \mathrm{j}}$ adalah demand produk kayu primer, $\mathrm{P}_{\mathrm{L}}$ adalah upah tenaga kerja, $\mathrm{P}_{\mathrm{E}}$ adalah harga riil bahan bakar.

Pasar input (pasar kayu bulat) terdiri dari pasar kayu bulat hutan alam, pasar kayu bulat HTI perkakas, dan pasar kayu bulat HTI pulp. Sedangkan pasar output (pasar produk primer kayu) terdiri dari pasar kayu lapis, pasar kayu gergaji dan pasar pulp.

Model yang digunakan untuk mendapatkan nilai penduga parameter terbaik, bebas autokorelasi yaitu (1) OLS, (2) OLS + AR(1), (3) 2SLS dan
(4) $2 \mathrm{SLS}+\mathrm{AR}(1)$. Sedangkan persamaan yang digunakakan yaitu :

(1) Persamaan logaritma natural: $\quad \mathrm{Ln}_{-} \mathrm{Q}_{\mathrm{l}}=\mathrm{ln}$ $\alpha_{0}+\alpha_{1} \ln \_P_{t}+\alpha_{2} \ln _{-} I_{t}+\alpha_{3} \ln \_G D P+e_{t}$,

(2) Persamaan logaritma dengan rasio tanpa konstanta:

$\mathrm{Ln} \_\mathrm{Q}_{\mathrm{t}}-\mathrm{Ln} \mathrm{Q}_{\mathrm{t}-1}=\ln \left(\mathrm{Q}_{\mathrm{t}} / \mathrm{Q}_{\mathrm{t}-1}\right)=\alpha_{1} \ln \left(\mathrm{P}_{\mathrm{t}} / \mathrm{P}_{\mathrm{t}-}\right.$ $\left.{ }_{1}\right)+\alpha_{2} \ln \left(\mathrm{I}_{\mathrm{t}} / \mathrm{I}_{\mathrm{t}-1}\right)+\alpha_{3} \ln \left(\mathrm{GDP}_{\mathrm{t}} / \mathrm{GDP}_{\mathrm{t}-1}\right)+\mathrm{e}_{\mathrm{t}}$

(3) Persamaan logartima natural dengan rasio dan konstanta

Ln_Q $\mathrm{Q}_{\mathrm{t}}-\mathrm{Ln} \_\mathrm{Q}_{\mathrm{t}-1}=\ln \left(\mathrm{Q}_{\mathrm{t}} / \mathrm{Q}_{\mathrm{t}-1}\right)=\mathrm{k}+\alpha_{1} \ln \left(\mathrm{P}_{\mathrm{t}} / \mathrm{P}_{\mathrm{t}}\right.$ $\left.{ }_{1}\right)+\alpha_{2} \ln \left(\mathrm{I}_{t} / \mathrm{I}_{\mathrm{t}-1}\right)+\alpha_{3} \ln \left(\mathrm{GDP}_{\mathrm{t}} / \mathrm{GDP}_{\mathrm{t}-1}\right)+\mathrm{e}_{\mathrm{t}}$

Pada sistem persamaan simultan antar variabel saling berkaitan (Koutsoyiannis, 1977). Persamaan diolah dengan program RATS untuk mendapatkan estimasi paramater. Parameter dugaan $\alpha$ dan $\beta$ merupakan nilai penduga elastisitas demand dan elastisitas supply. Selanjutnya nilai dugaan $\alpha$ dan $\beta$ diperiksa kemungkinanan adanya autokorelasi. Autokorelasi biasanya muncul pada persamaan yang menggunakan data time series (Verbeek, 2004). Pengujian adanya autokorelasi menggunakan Durbin-Watson (DW). Sekiranya masih ada autokorelasi maka harus diperbaki dengan pengujian autokorelasi tingkat $1 \mathrm{AR}(1)$. Tahapan untuk mendapatkan estimasi parameter model persamaan:

(1) Melakukan pengolahan data menggunakan program statistik RATS

(2) Memeriksa apakah asumsi-asumsi penduga parameter terpenuhi.

(3) Memeriksa apakah semua penduga parameter yang dihasilkan sesuai dengan teori ekonomi, sebagaimana tabel 2.

Tabel 1. Elastisitas demand jangka panjang untuk hasil hutan

\begin{tabular}{|c|c|c|c|c|c|c|c|c|c|c|c|c|c|}
\hline \multirow{2}{*}{$\begin{array}{l}\text { Elasticity/ } \\
\text { Product }\end{array}$} & \multicolumn{2}{|c|}{ 1) } & \multirow[t]{2}{*}{ 2) } & \multirow[t]{2}{*}{ 3) } & \multirow[t]{2}{*}{ 4) } & \multirow[t]{2}{*}{ 5) } & \multirow[t]{2}{*}{ 6) } & \multirow[t]{2}{*}{ 7) } & \multicolumn{2}{|c|}{ 8) } & \multirow[t]{2}{*}{ 9) } & \multirow[t]{2}{*}{ 10) } & \multirow{2}{*}{ Median } \\
\hline & a) & b) & & & & & & & a) & b) & & & \\
\hline \multicolumn{14}{|l|}{ Price elasticity } \\
\hline Sawn & & & & & & & & -0.80 & & & & -0.22 & -0.51 \\
\hline Sawn, c & & & -0.21 & -0.72 & & -0.24 & & -1.13 & 0.38 & -0.46 & & & -0.35 \\
\hline Sawn, nc & & & -0.16 & -0.90 & & -0.16 & & -0.53 & -1.00 & -0.07 & & & -0.35 \\
\hline Panels & & & & -0.37 & & & & & & & & & -0.37 \\
\hline Ply & & & 0.15 & & & -0.55 & & -0.18 & -0.09 & -0.25 & & -0.25 & -0.21 \\
\hline Part & & & -0.14 & & & -0.09 & & -0.17 & 0.00 & -0.69 & & & -0.14 \\
\hline Fiber & & & -0.17 & & & 0.08 & & -1.11 & -0.26 & -0.68 & & & -0.26 \\
\hline News & -0.75 & -0.59 & & -1.15 & -0.30 & -0.05 & -0.72 & -0.76 & -0.27 & -0.13 & -0.48 & -0.18 & -0.48 \\
\hline Print & -0.74 & -0.21 & & -0.78 & 0.00 & 0.00 & -0.49 & -0.70 & -0.26 & -0.09 & -0.89 & -0.27 & -0.27 \\
\hline Opap & -0.83 & -0.29 & & -0.88 & -0.01 & -0.29 & -0.72 & -0.45 & 0.00 & -0.69 & -0.30 & -0.10 & -0.30 \\
\hline \multicolumn{14}{|l|}{ GDP elasticity } \\
\hline Sawn & & & & & & & & 0.91 & & & & 0.50 & 0.71 \\
\hline Sawn, c & & & 0.71 & 1.57 & & 1.41 & & 0.85 & 0.16 & 0.28 & & & 0.78 \\
\hline Sawn, nc & & & 0.53 & 0.88 & & 1.26 & & 0.25 & 0.77 & 0.81 & & & 0.79 \\
\hline Panels & & & & 1.37 & & & & & & & & & 1.37 \\
\hline Ply & & & 1.02 & & & 1.46 & & 0.30 & 0.10 & 1.47 & & 0.86 & 0.94 \\
\hline Part & & & 2.32 & & & 3.08 & & 0.60 & 0.97 & 1.02 & & & 1.02 \\
\hline Fiber & & & 1.07 & & & 1.70 & & 0.14 & 1.38 & 1.55 & & & 1.38 \\
\hline News & 1.07 & 0.84 & & 1.23 & 0.84 & 1.08 & 0.95 & 1.14 & 0.73 & 1.54 & 0.63 & 1.07 & 1.07 \\
\hline Print & 1.20 & 1.56 & & 1.24 & 1.52 & 1.31 & 1.03 & 1.29 & 1.52 & 1.47 & 1.07 & 1.55 & 1.31 \\
\hline Opap & 1.65 & 1.41 & & 1.24 & 0.62 & 1.59 & 0.98 & 1.00 & 1.61 & 1.02 & 0.41 & 1.30 & 1.24 \\
\hline $\begin{array}{l}\text { 1) Buongiorno (1 } \\
\text { 2) Buongiorno (1 } \\
\text { 3) Wibe (1984), } \\
\text { 4) Uutela (1987) } \\
\text { 5) Buongiorno a } \\
\text { 6) Baudin and L } \\
\text { 7) Prestemon an } \\
\text { 8) Brooks et al. } \\
\text { 9) Chas-Amil an }\end{array}$ & $\begin{array}{l}8), 43 \mathrm{cc} \\
\text { 9), } 43 \mathrm{c} \\
3 \text { countr } \\
\text { countr } \\
\text { Chang ( } \\
\text { berg (1 } \\
\text { buongior } \\
5 \text { ), } 8 \mathrm{cc} \\
\text { uongior }\end{array}$ & $\begin{array}{l}\text { untries, } \\
\text { untries, } \\
\text { es, } 1976 \\
\text { se, } 1965 \\
986), 1 \\
87), \text { ma } \\
\text { oo (1993 } \\
\text { untries, } \\
\text { o (2000 }\end{array}$ & $\begin{array}{l}1963-19 \\
1963-19 \\
-1979 . \\
-1980 . \\
\text { o OECD } \\
\text { jor consu } \\
3,24 \text { co } \\
1964-19\end{array}$ & $\begin{array}{l}73, \\
73\end{array}$ & ince & e, b) & thin-c & ntry e & ates. & & & & \\
\hline
\end{tabular}


Tabel 2. Ekspektasi tanda parameter

\begin{tabular}{|c|c|c|c|c|c|c|c|c|c|c|c|c|c|c|c|}
\hline \multirow{2}{*}{ Persamaan } & \multicolumn{10}{|c|}{ Variabel } \\
\hline & PT1 & PT2 & PT3 & I1 & I2 & I3 & PQ1 & PQ2 & PQ3 & PL & PE & QKL & QKG & QP & GDP \\
\hline Supply & & & & & & & & & & & & & & & \\
\hline QT1 & + & & & + & & & & & & & & & & & + \\
\hline QT2 & & + & & & + & & & & & & & & & & + \\
\hline QT3 & & & + & & & + & & & & & & & & & + \\
\hline QKL & - & & & & & & + & & & - & - & & & & \\
\hline QKG & - & & & & & & & + & & - & - & & & & \\
\hline QP & & & - & & & & & & + & - & - & & & & \\
\hline Demand & & & & & & & & & & & & & & & \\
\hline QT1 & - & & & & & & & & & & & + & + & & + \\
\hline QT2 & & - & & & & & & & & & & + & + & & + \\
\hline QT3 & & & - & & & & & & & & & & & + & + \\
\hline QKL & & & & & & & - & & & & & & & & + \\
\hline QKG & & & & & & & & - & & & & & & + \\
\hline QP & & & & & & & & & - & & & & & + & + \\
\hline
\end{tabular}

\section{Sumber dan Jenis Data}

Data utama yang dalam penelitian ini adalah data sekunder time series pengamatan tahun 1995 sampai 2009, berasal dari berbagai laporan dan publikasi, statistik Kehutanan Indonesia, Badan Pusat Statistik dan laporan Food Agriculture Organization (FAO), serta referesensi lain seperti ITTO

\section{HASIL DAN PEMBAHASAN}

\section{Hasil Pendugaan Parameter}

Setelah dilakukan proses pengolahan menggunakan program RATS, dilakukan koreksi autokorelasi dan diperiksa tanda parameter maka hasilnya dapat dilihat pada tabel 3.

Tabel 3. Nilai penduga parameter

\begin{tabular}{|c|c|c|c|c|c|c|c|c|c|c|c|c|c|c|c|}
\hline \multirow{2}{*}{ Persamaan } & \multicolumn{15}{|c|}{ Variabel } \\
\hline & PT1 & PT2 & PT3 & 11 & 12 & 13 & PQ1 & PQ2 & $P Q 3$ & $\mathrm{PL}$ & $P E$ & QKL & QKG & $Q P$ & GDP \\
\hline \multicolumn{16}{|l|}{ Supply } \\
\hline QT1 & \begin{tabular}{|l|}
0.38 \\
\end{tabular} & & & $4.13^{*}$ & & & & & & & & & & & $1.02 *$ \\
\hline QT2 & & $\underline{1.02}$ & & & 4.13* & & & & & & & & & & 2.96 \\
\hline QT3 & & & 0.70 & & & $4.13 *$ & & & & & & & & & 3.06 \\
\hline QKL & -0.002 & & & & & \multicolumn{3}{|c|}{$1.28^{* *}$} & & -0.06 & -0.17 & & & & \\
\hline QKG & -0.18 & & & & & & & \begin{tabular}{|l|}
0.05 \\
\end{tabular} & & -0.19 & -0.11 & & & & \\
\hline$Q P$ & & & -0.41 & & & & & & $\underline{0.49}$ & -2.46 & $-1.19^{*}$ & & & & \\
\hline \multicolumn{16}{|l|}{ Demand } \\
\hline QT1 & $0.11^{*}$ & & & & & & & & & & & $\underline{1.95}$ & 2.31 & & \\
\hline QT2 & \multicolumn{3}{|c|}{$-0.11 *$} & & & & & & & & & 3.22 & $0.61^{*}$ & & \\
\hline QT3 & & & -0.06 & & & & & & & & & & & $\underline{\underline{1.17}}$ & \\
\hline QKL & & & & & & & -0.18 & & & & & & & & 0.23 \\
\hline QKG & & & & & & & & -0.08 & & & & & & & 1.01 \\
\hline QP & & & & & & & & & -0.29 & & & & & & $\underline{2.82}$ \\
\hline
\end{tabular}

Keterangan:

* Data diperoleh dari Simangunsong (2001)

** Data diperoleh dari Manurung (1995)

\section{Pasar Input (Pasar Kayu Bulat)}

Dari hasil pengolahan data, sebagaimana disajikan pada tabel 2, maka semua tanda nilai penduga parameter untuk pasar input dan pasar input sebagian besar sesuai teori ekonomi. Sebagian kecil, yang tidak sesuai teori ekonomi maka nilai penduga parameter tidak bisa digunakan, harus menggunakan pustaka. Beberapa nilai penduga parameter yang digaris bawah bersifat sangat nyata, dengan nilai kesalahan $(\alpha)$ sebesar $5 \%$.

(1) Pasar Kayu Bulat Hutan Alam

Kayu bulat yang berasal dari hutan alam merupakan sumber utama bahan baku industri kayu lapis dan kayu gergaji. Jumlah produksi 
kayu bulat hutan alam (QT1) ditentukan oleh harga kayu bulat (PT1), stok kayu bulat (I1) dan daya beli (GDP). Semakin tinggi harga kayu bulat hutan alam dan semakin banyak stok kayu bulat di hutan alam serta semakin tinggi daya beli, maka perusahaan akan meningkatkan supplynya. Dengan nilai penduga parameter Ln_PT1 $=0.38$, jika harga kayu bulat naik sebesar 1 persen maka akan jumlah produksi kayu bulat naik 0.38 persen. Dengan nilai dugaan parameter I1=4.1 dan GDP=1 (Simangunsong, 2001), jika stok kayu bulat meningkat 1 persen maka produksi kayu bulat akan meningkat 4.1 persen. Jika daya beli meningkat 1 persen maka produksi kayu bulat juga meningkat 1 persen.

Jumlah permintaan kayu bulat hutan alam (QT1) ditentukan oleh produksi kayu lapis (QKL), produksi kayu gergaji (QKG) dan harga kayu bulat (PT1). Semakin tinggi produksi kayu lapis dan kayu gergaji serta semakin rendah harga kayu bulat maka akan meningkatkan permintaan kayu bulat. Dengan nilai penduga parameter Ln_QKL $=1.95$, jika jumlah permintaan kayu lapis meningkat 1 persen maka permintaan kayu bulat meningkat 1.95 persen dan nilai penduga parameter Ln_QKG=2.31, jika jumlah permintaan kayu gergaji meningkat 1 persen maka permintaan kayu bulat meningkat 2.31 persen. Dengan nilai penduga parameter PT1=0.11 (Simangunsong, 2001), jika kenaikan harga kayu bulat 1 persen maka permintaan kayu bulat turun 0.11 persen.

(2) Pasar Kayu Bulat HTI Perkakas

Kayu bulat dari HTI perkakas merupakan bahan baku untuk menghasilkan kayu lapis dan kayu gergaji. Jumlah produksi kayu bulat HTI perkakas (QT2) akan tergantung harga kayu (PT2), luas HTI (I2) dan daya beli (GDP). Produksi kayu bulat oleh perusahaan akan meningkat apabila harga kayu bulat, luas HTI perkakas dan daya beli juga meningkat. Dengan nilai penduga parameter Ln_PT2 $=1.02$, jika harga kayu bulat naik sebesar 1 persen maka produksi kayu bulat naik 1 persen. Dengan nilai penduga parameter Ln_GDP=2.96, jika daya beli meningkat sebesar 1 persen maka produksi naik hampir 3 persen. Dengan penduga parameter $\mathrm{I} 2=4.13$ (Simangunsong, 2000), jika stok kayu bulat meningkat 1 persen maka produksi kayu bulat meningkat 4 persen.

Jumlah permintaan kayu bulat HTI perkakas (QT2) ditentukan oleh produksi kayu lapis
(QKL), produksi kayu gergaji (QKG) dan harga kayu bulat (PT2). Semakin tinggi produksi kayu lapis dan kayu gergaji serta semakin rendah harga kayu bulat maka akan meningkatkan permintaan kayu bulat. Dengan nilai penduga parameter Ln_QKL=3.22, jika produksi kayu lapis meningkat 1 persen maka permintaan kayu bulat meningkat 3.22 persen dan dengan nilai penduga parameter $\mathrm{QKG}=0.61$ (Simangunson, 2001), jika produksi kayu gergaji meningkat 1 persen maka permintaan kayu bulat meningkat 0.61 persen. Dengan nilai penduga parameter Ln_PT $=-0.11$, jika harga kayu bulat meningkat 1 persen maka permintaan kayu bulat turun 0,11 persen.

\section{(3) Pasar Kayu Bulat HTI Pulp}

Jumlah produksi kayu bulat dari HTI pulp (QT3) ditentukan oleh harga kayu bulat (PT3), luas HTI pulp dan daya beli (GDP). Produksi kayu bulat oleh perusahaan akan meningkat apabila harga kayu bulat, luas HTI pulp dan daya beli juga meningkat. Dengan nilai penduga parameter Ln_PT3 $=0.70$, jika harga kayu bulat meningkat 1 persen maka produksi kayu bulat meningkat 0.70 persen. Dengan nilai penduga parameter Ln_GDP 3.06, jika daya beli meningkat 1 persen maka produksi kayu bulat meningkat 3,06 persen. Dan penduga parameter I3=4.13 (Manurung, 1995), jika luas HTI pulp meningkat 1 persen maka produksi kayu bulat meningkat 4.13 persen.

Jumlah permintaan kayu bulat HTI pulp (QT3) ditentukan oleh produksi pulp (QP) dan harga kayu bulat pulp (PT3). Dengan nilai penduga parameter Ln_QP=1.17, jika produksi pulp meningkat 1 persen maka produksi kayu bulat pulp meningkat 1.17 persen. Dengan nilai penduga parameter Ln_PT3=-0.06, jika harga kayu bulat pulp menigkat 1 persen maka produksi kayu bulat pulp turun 0.06 persen.

\section{Pasar Output (Pasar Produk Primer Kayu)}

(1) Pasar Kayu Lapis

Kayu lapis merupakan produksi andalan dari industri perkayuan. Jumlah produksi kayu lapis (QKL) ditentukan oleh harga kayu lapis (PQ1), upah tenaga kerja (PL), harga kayu bulat (PT1) dan harga bahan bakar (PE). Semakin tinggi harga kayu lapis, maka semakin meningkat produksi kayu lapis, dan semakin rendah upah tenaga kerja, harga kayu bulat dan harga bahan bakar maka semakin tinggi produksi kayu lapis. Dengan nilai parameter PQ1 $=0.002$ (Manurung, 1995), jika harga kayu lapis meningkat 1 persen, maka produksi kayu lapis meningkat 0.002 
persen. Dengan nilai penduga parameter Ln_PL=-0.06, jika upah tenaga kerja meningkat 1 persen, maka produksi kayu lapis turun 0.06 persen. Dengan nilai penduga parameter Ln_PT1 $=-0.002$, jika harga kayu bulat meningkat 1 persen maka produksi kayu lapis turun 0.002 . Dengan nilai penduga Ln_PE=-1.17, jika harga bahan bakar energi meningkat 1 persen maka produksi kayu lapis turun 1.17 persen.

Jumlah permintaan kayu lapis (QKL) ditentukan oleh daya beli (GDP) dan harga kayu lapis (PQ1). Semakin tinggi daya beli dan semakin rendah harga kayu lapis maka akan meningkatkan jumlah permintaan kayu lapis. Dengan nilai penduga parameter Ln_GDP $=0.23$, jika daya beli naik 1 persen maka permintaan kayu lapis meningkat 0.23 . Dengan nilai penduga parameter Ln_PQ1=-0.18, jika harga kayu lapis meningkat 1 persen, maka permintaan kayu lapis turun 18 persen.

(2) Pasar Kayu Gergaji

Industri kayu gergaji jumlah banyak sekali dibandingkan industri kayu lapis dan pulp, membutuhkan bahan baku yang cukup besar. Jumlah produksi kayu gergaji (QKG) ditentukan oleh harga kayu gergaji (PQ2), upah tenaga kerja (PL), harga kayu bulat (PT1) dan harga bahan bakar (PE). Semakin tinggi harga kayu gergaji semakin meningkat produksi kayu gergaji, dan semakin rendah upah tenaga kerja, harga kayu bulat dan harga bahan bakar maka semakin tinggi produksi kayu gergaji. Dengan nilai penduga parameter Ln_PQ2 $=0.05$, jika harga kayu gergaji meningkat 1 persen maka produksi kayu gergaji naik 0.05 persen. Dengan nilai penduga parameter Ln_PL $=-0.19$, jika upah tenaga kerja meningkat 1 persen maka produksi kayu gergaji turun 0.19 persen. Dengan nilai penduga parameter Ln_PT1=-0.18, jika harga kayu bulat meningkat 1 persen maka produksi kayu gergaji turun 0.18 persen. Dengan nilai penduga parameter $\mathrm{PE}=-1.19$ (Manurung, 1995), jika harga bahan bakar meningkat 1 persen maka produksi kayu gergaji turun 1.19 persen.

Permintaan kayu gergaji (QKG) ditentukan oleh daya beli (GDP) dan harga kayu gergaji (PQ2). Semakin tinggi daya beli dan semakin rendah harga kayu gergaji akan meningkatkan jumlah permintaan gergaji. Dengan nilai penduga parameter Ln_GDP=1.01, jika daya beli meningkat 1 persen, maka permintaan kayu gergaji meningkat 1 persen. Nilai penduga parameter Ln_PQ2 $=-0.08$, jika harga kayu gergaji nail 1 persen maka permintaan kayu gergaji turun 0.08 persen.

\section{(3) Pasar Pulp (QP)}

Jumlah produksi pulp (QP) tergantung tingkat harga pulp (PQ3), upah tenaga kerja (PL), harga kayu bulat (PT3) dan harga bahan bakar (PE). Semakin tinggi harga pulp, semakin meningkat produksi pulp, dan semakin rendah upah tenaga kerja, harga kayu bulat dan harga bahan bakar maka semakin tinggi produksi pulp. Dengan nilai penduga parameter Ln_PQ3 $=0.49$, jika harga pulp meningkat 1 persen maka produksi pulp meningkat 0.49 persen. Dengan nilai penduga parameter Ln_PL=-2.46, jika upah tenaga kerja meningkat 1 persen maka produksi pulp turun 2.46 persen. Dengan nilai penduga parameter Ln_PT1=-0.41, jika harga kayu bulat meningkat 1 persen maka produksi pulp turun 0.41 persen. Dengan nilai pernduga parameter $\mathrm{PE}=-1.19$ (Simangunsong, 2000), jika harga bahan bakar meningkat 1 persen maka produksi pulp turun 1.19 persen.

Jumlah permintaan pulp (QP) ditentukan oleh daya beli (GDP) dan harga pulp (PQ3). Semakin tinggi daya beli dan semakin rendah harga pulp maka akan meningkatkan jumlah permintaan pulp. Dengan nilai penduga parameter Ln_GDP=2.82, jika daya beli meningkat 1 persen maka permintaan pulp meningkat 2.82 persen. Nilai penduga parameter Ln_PQ3 =-0.29 jika harga pulp meningkat 1 persen maka permintaan pulp turun 0.29 persen.

Berdasarkan hasil penelitian elastisitas demand di beberapa negara (tabel 1) dibandingkan hasil penelitian ini (tabel 3), nilai tengah elastisitas harga untuk kayu plywood 0.21 , lebih kecil dibandingkan hasil penelitian 0.18 dan kayu gergaji -0.35 , lebih kecil dibanding hasil penelitian -0.08 , keduanya bersifat inelastis. Sedangkan nilai tengah elastisitas GDP di beberapa negara untuk kayu lapis 0.94, lebih besar dari hasil penelitian ini 0.23 , keduanya bersifat inelastis. Elastisita GDP di beberapa negara untuk kayu gergaji 0.79 , bersifat inelastis dibandingkan hasil penelitian ini, bersifat unit elastis, Untuk menghasilkan kayu lapis, kayu gergaji dan pulp membutuhkan bahan baku utama kayu bulat, yang sampai saat ini masih belum bisa digantikan (substitusi) oleh barang lain sehingga bersifat inelastic dibandingkan produk lain yang memiliki substitusi.

\section{SIMPULAN}

Model yang digunakan untuk mendapatkan nilai penduga parameter terbaik, bebas 
autokorelasi dan tandanya sesuai dengan teori ekonomi, menggunakan model persamaan simultam (2SLS). Apabila tidak diperoleh nilai penduga parameter terbaik, maka menggunakan model persamaan tunggal (OLS). Parameter yang tidak memenuhi harapan tidak digunakan, dan menggunakan data pustaka.

Pada umumnya harga bahan baku bulat bersifat inelastis, stok bersifat elastis, harga industri primer hasil hutan bersifat inelastis, jumlah produk industri primer hasil hutan bersifat elastis, GDP bersifat elastis, serta biaya upah dan bahan bakar bersifat inelastis.

Nilai elastisitas harga plywood dan kayu gergaji bersifat inelastis, sama dengan nilai elastisitas hasil penelitian di beberapa negara. Nilai tengah elastisitas harga plywood di berapa negara sebesar -0.21 , lebih kecil dibandingkan hasil penelitian sebesar -018. Nilai tengah elastisitas hasil penelitian di beberapa negara untuk kayu gergaji sebesar -0.35 , lebih kecil dibanding hasil penelitian ini sebesar -0.08 . Nilai tengah elastisitas GDP hasil penelitian di beberapa negara untuk kayu lapis sebesar 0.94, lebih besar dari hasil penelitian ini sebesar 0.23. Nilai tengah elastisitas GDP kayu gergaji hasil penelitian di beberapa negara sebesar 0.79 , dibandingkan hasil penelitian ini, sebesar 1 . Nilai penduga elastisitas ini dapat digunakan untuk melakukan kajian kebijakan pemerintah terhadap industri berbasis kayu.

\section{DAFTAR PUSTAKA}

Badan Pusat Statistik.(2005). Statistik Indonesia 2004. Badan Pusat Statistik, Jakarta.

Badan Pusat Statistik.(2015). Statistik Indonesia 2015. Badan Pusat Statistik, Jakarta.

Bisnis Indonesia.(2009). Penerimaan DR \& PSDH baru $40 \%$. Selasa 8 September 2009.

(http://www.pajakonline.com/engine/arti kel/art.php?artid=6403).

Departemen Kehutanan. 2007. Eksekutif Data Strategis Kehutanan 2007. Departemen Kehutanan, Jakarta.

Food Agriculture Organization. 2011. FAOISTAT Database home page (http://www.fao.org/) FAO, Rome.

Kementerian Lingkungan Hidup dan Kehutanan. 2016. Stattistik Kementerian Lingkungan Hidup dan Kehutanan Tahun 2015. Pusat Data dan Informasi, Kementerian dan Kehutanan, Jakarta.
McGuyan, James R., Moyer R. Charles. 1986. Managerial Economics. Fourth Edition. West Publising Co, Saint Paul, Minnesota, USA.

Manurung, E.G.T. 1995. Economic Impact of the Log Export Ban Policy on The Development of Forest Products Industries of Indonesia. Ph.D. Dissertation. University of Wisconsin, Madison.

Pindyck, R.S., and D.L. Rubinfeld. 2013. Microeconomics. Eighth Edition. Person Education, Inc., New Jersey.

Rusli, Y. 1999. The Indonesian Plywood Industry, Environmental Conservation Policy, and the Long-Run Market Adjustment. Ph.D. Dissertation. University of Washington.

Samoelson, W.F., and Stephen, G.M. 2012. Managerial Economics, Seven Edition. John Willey \& Sons, Inc.,

Simangunsong, B.C.H. 2001. International Demand and Supply for Forest Products, with Applications to the Tropical Timber Priducts Trade. Ph.D. Dissertation. University of Wisconsin, Madison.

Sinaga, B.M. 1989. Econometric Model of the Indonesian Hardwood Products Industry: A Policy Simulation Analysis. Ph.D. Dissertation. University of The Philippines, Los Banos.

Verbeek, M. 2004. Modern Econometrics. A Guide to Modern Econometrics. 2nd edition. Erasmus University Rotterdam. John Wiley \& Sons. Ltd, England.

Timotius. 2000. Analisis Ekonometrika Perkembangan industri Kayu Lapis Indonesia 1975-2010: Suatu Simulasi Kebijakan. Disertasi Doktor. Program Pascasarjana. Institut Pertanian Bogor, Bogor.

Turner, J,A., J. Buongiorno, S. Zhu. 2006. An Economic Model Of International Wood Supply, Forest Stock And Forest Area Change. Scandinavian Journal Of Forest Research, 2 (1) : $73-86$.

Wear, D.N., Parks, P. J.1994. The Economics of Timber Supply: An Analytical Synthesis of Modeling Approaches. Natural Resource Modeling, Volume 8, Number 5: 199 -223. 